\title{
Comparative study of the morphology and properties of PP/LLDPE/wood powder and MAPP/LLDPE/wood powder polymer blend composites
}

\author{
D. G. Dikobe, A. S. Luyt* \\ Department of Chemistry, University of the Free State (Qwaqwa Campus), Private Bag X13, Phuthaditjhaba, 9866 , \\ South Africa
}

Received 1 June 2010; accepted in revised form 13 August 2010

\begin{abstract}
In this study, polypropylene (PP)/linear low-density polyethylene (LLDPE) and maleic anhydride grafted polypropylene (MAPP)/LLDPE blend systems were comparatively investigated. The blends and composites contained equal amounts of the two polymers, and the compatibility and miscibility between the two polymers were investigated. Composites with 10, 20 and $30 \mathrm{wt} \%$ wood powder (WP), but still with equal amounts of the two polymers, were prepared and investigated. The morphologies, as well as mechanical and thermal properties, of the blends and the blend composites were investigated. The MAPP/LLDPE blend and composites showed better properties than the PP/LLDPE blend and composites as a result of the stronger interfacial interaction between MAPP, LLDPE and WP. The SEM and DSC results of the PP/LLDPE/WP blend composites showed that WP located itself more in the LLDPE phase. In the MAPP/LLDPE/WP composites the WP was in contact with both polymers, although it had a greater affinity for MAPP. The TGA results show that the MAPP/LLDPE blend and composites are more thermally stable than the PP/LLDPE blend and composites.
\end{abstract}

Keywords: polymer composites, polypropylene, maleic anhydride grafted polypropylene, linear low-density polyethylene, wood powder

\section{Introduction}

The blending of two or more polymers is a cheaper and more effective alternative, not only for the development of polymers with new properties, but also for recycling of greener materials [1-3]. Polypropylene/polyethylene (PP/PE) blends are amongst polymer blends that were studied by various researchers [4-6]. Three different types of PE, namely low-density polyethylene (LDPE), highdensity polyethylene (HDPE), and linear low-density polyethylene (LLDPE) were used to modify the physical and mechanical behaviour of PP by forming physical blends [2]. The interest in PP and $\mathrm{PE}$ is specifically due to the fact that both these polymers are widely used as important engineering materials in the automotive, electrical appliances and packaging industries due to their excellent properties such as rigidity and stiffness, oil resistance and their thermal stability [7]. Apart from these good properties that PP has, its applications are often limited due to its low impact strength and Young's modulus, particularly at low and high temperature loading conditions. These PP drawbacks can be considerably improved by blending PP with other polymers [7-9].

Blending of PP and different PEs largely depends on the miscibility or immiscibility of the two components. PP and LDPE or HDPE are generally considered immiscible in the whole composition range and shows a remarkable phase separation during 
cooling/crystallization $[2,7,9]$. On the other hand, PP and LLDPE are considered to be compatible in the liquid state. However, PP/LLDPE miscibility is restricted by the processing conditions, composition and high temperatures. If a blend of PP and LLDPE is cooled from a miscible melt it may separate into two phases resulting in an immiscible blend [10].

The incorporation of fillers into thermoplastics is another method widely used to enhance certain properties. The degree of property enhancement depends on the filler particle size and shape, the content of filler, the surface treatment promoting interaction between the polymer matrix and filler and most importantly the filler's origin [11]. Natural fibres are favoured over synthetic fibres due to strict environmental policies that promote the manufacturing of biodegradable materials. One of the disadvantages of using natural fibres is that they are incompatible with hydrophobic thermoplastics. MA-maleated PP (MAPP) has been widely used at low concentrations as a compatibilizing agent and adhesion promoter for bio-filler filled polypropylene composites. The maleic anhydride (MA) functional group which grafts onto the PP backbone acts as a chemical link between the hydrophobic matrix polymer and the hydrophilic surface of natural fillers [12-17].

Two ways used to improve polymer properties are polymer blending and the use of filler to form polymer composites. These two methods were extensively, but separately used. Studies dealing with polymer blends reinforced with rigid fillers to give three-phase polymer composites are still fairly new [18]. In cases where these studies were done, synthetic and mineral fibres such as talc, glass fibre and calcium carbonate $\left(\mathrm{CaCO}_{3}\right)$ were used as fillers [18-21]. Very few studies of ternary systems involving natural fibres as reinforcement were reported [11, 22-25].

In this study, PP/LLDPE and MAPP/LLDPE blend systems, where the two polymers in each system were mixed in equal quantities, were comparatively investigated. This work was primarily a study on the interaction of wood powder (WP) particles with one or more of the phases of different $50 / 50 \mathrm{w} / \mathrm{w}$ polyolefin blends, and of the influence of the presence of WP particles and the respective interactions on the crystallization and melting behaviour of the different polymers in the blends. Maleic anhydride grafted polypropylene (MAPP) was introduced to compare the properties of PP/PE blend composites when one of the polymer phases (PP) is replaced by its functionalized equivalent (MAPP). The morphologies, thermal stabilities and mechanical properties of the blends and blend composites were also investigated.

\section{Experimental}

\subsection{Materials}

MAPP, supplied by Pluss Polymers Pvt. Ltd. (India), has a density of $0.91 \mathrm{~g} \cdot \mathrm{cm}^{-3}$, a melting point of $161^{\circ} \mathrm{C}$, a tensile strength of $24 \mathrm{MPa}$ and a melt flow index (MFI) of $55 \mathrm{~g} / 10 \mathrm{~min}\left(190^{\circ} \mathrm{C}\right.$, $2.16 \mathrm{~kg}$ ). PP, supplied by Sasol Polymers (Johannesburg, South Africa) has a density of $0.90 \mathrm{~g} \cdot \mathrm{cm}^{-3}$, a melting point of $165^{\circ} \mathrm{C}$ and MFI of $12 \mathrm{~g} / 10 \mathrm{~min}$ $\left(230^{\circ} \mathrm{C}, 2.16 \mathrm{~kg}\right)$. LLDPE, supplied by Sasol Polymers (Johannesburg, South Africa) has a density of $0.94 \mathrm{~g} \cdot \mathrm{cm}^{-3}$, a melting point of $127^{\circ} \mathrm{C}$ and an MFI of $3.5 \mathrm{~g} / 10 \mathrm{~min}\left(190^{\circ} \mathrm{C}, 2.16 \mathrm{~kg}\right)$. Pine wood powder (WP), or pine saw dust, was obtained from FBW Taurus (Phuthaditjhaba, South Africa). WP was supplied as a light orange coloured powder with a density of $1.5 \mathrm{~g} \cdot \mathrm{cm}^{-3}$ and was dried at $120^{\circ} \mathrm{C}$ for 48 hours. Particles with sizes $\leq 150 \mu \mathrm{m}$ were obtained by sieving the dried WP using a laboratory test sieve of $150 \mu \mathrm{m}$ pore size.

\subsection{Preparation of the blends and composites}

The blends and blend composites were weighed according to the required ratios $(100 / 0 / 0,0 / 100 / 0$, 50/50/0, 45/45/10, 40/40/20, 35/35/30 w/w PP/ LLDPE/WP and MAPP/LLDPE/WP) to make up a total of $38 \mathrm{~g}$ (which is the mass required for thoroughly mixing the different components in the Brabender Plastograph $50 \mathrm{ml}$ mixer). Mixing of the samples was done at a temperature of $180^{\circ} \mathrm{C}$ and a mixing speed of $30 \mathrm{rpm}$ for 15 minutes. The samples were then melt pressed at $190^{\circ} \mathrm{C}$ and $100 \mathrm{bar}$ for 3 minutes. The pressed samples were allowed to cool at room temperature for 10 minutes.

\subsection{Composite analysis}

The morphologies of the 50/50 w/w PP/LLDPE and MAPP/LLDPE blends and the 40/40/20 w/w PP/LLDPE/WP and MAPP/LLDPE/WP blend com- 
posites were examined using a Shimadzu SSX-550 Superscan scanning electron microscope (SEM) (Bangkok, Thailand). Each sample was immersed in liquid nitrogen to ensure perfect breakage. The fractured surface was sputter coated with gold dust (between 20 and $60 \mathrm{~nm}$ ) before viewing.

Differential scanning calorimetric (DSC) analyses were carried out in a Perkin-Elmer DSC7 (Waltham, Massachusetts, USA) under flowing nitrogen $\left(20 \mathrm{ml} \cdot \mathrm{min}^{-1}\right)$. Samples with masses of approximately $7.5 \mathrm{mg}$ were heated from 25 to $190^{\circ} \mathrm{C}$ at a rate of $10^{\circ} \mathrm{C} \cdot \mathrm{min}^{-1}$ in order to eliminate the thermal history, cooled to $25^{\circ} \mathrm{C}$ at $10^{\circ} \mathrm{C} \cdot \mathrm{min}^{-1}$, and reheated under the same conditions. Three different samples were analysed for each composition. The melting and crystallization data were obtained from the second scan, and the average and standard deviation values for each thermal property are reported.

Tensile testing was performed under ambient conditions on a Hounsfield H5KS universal tester at a cross-head speed of $50 \mathrm{~mm} \cdot \mathrm{min}^{-1}$. Tensile test specimens (gauge length $24 \mathrm{~mm}$, width $5 \mathrm{~mm}$, thickness $2 \mathrm{~mm}$ ) were prepared using a dumbbell shaped hollow punch. Six samples per composition were analysed.

For dynamic mechanical (DMA) analysis, rectangular samples of $50 \mathrm{~mm} \times 12.5 \mathrm{~mm} \times 2 \mathrm{~mm}$ were used. A Perkin Elmer Diamond DMA (Wellesley, Massachusetts, USA) was used for the evaluation of the storage modulus, loss modulus and mechanical damping factor. The temperature range over which the properties were measured was -100 to $100^{\circ} \mathrm{C}$ at a heating rate of $5^{\circ} \mathrm{C} \cdot \mathrm{min}^{-1}$ under $30 \mathrm{ml} \cdot \mathrm{min}^{-1}$ flowing nitrogen. The tests were carried out at a frequency of $1 \mathrm{~Hz}$.

Thermogravimetric analyses (TGA) were carried out using a Perkin-Elmer TGA7 (Waltham, Massachusetts, USA). Samples with masses of approximately $10 \mathrm{mg}$ were heated from 50 to $600^{\circ} \mathrm{C}$ at a

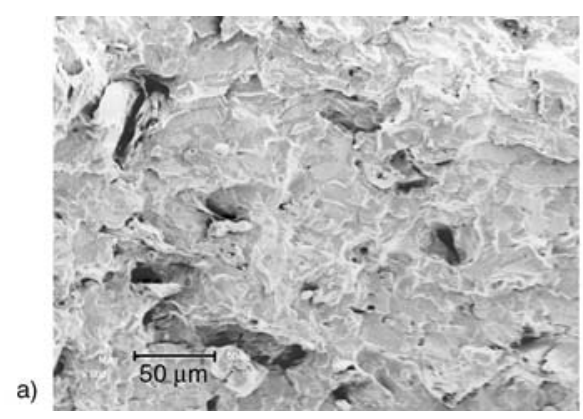

heating rate of $20^{\circ} \mathrm{C} \cdot \mathrm{min}^{-1}$ under flowing nitrogen $\left(20 \mathrm{ml} \cdot \mathrm{min}^{-1}\right)$.

\section{Results and discussion}

\subsection{Scanning electron microscopy (SEM)}

The morphology of immiscible polymer blends depends on the components, ratios, component melt viscosities, and processing conditions. In most heterogeneous systems, a morphology whereby one phase is distributed in another phase is observed. Long et al. [10] used polarized optical microscopy (POM) to study the morphology of PP/LLDPE blends and reported different morphologies when various contents of polymers were used. In a 90/10 w/w PP/LLDPE blend, PP spherulites were observed while LLDPE appeared as domains in the PP matrix. In blends where the PP content was lower, the PP spherulites disappeared and LLDPE became the continuous phase. Hassan et al. [26] used SEM to study the morphology of an $80 / 20 \mathrm{w} / \mathrm{w}$ PP/LLDPE binary blend and observed a discrete phase of LLDPE as domains sticking to the surface of the PP matrix. These droplets were quite uniformly distributed/dispersed rather than dissolved inside the PP matrix. The droplet formation shows that PP and LLDPE were immiscible and thus they were microscopically separated in the blends.

The SEM photos of the 50/50 w/w PP/LLDPE and MAPP/LLDPE systems are shown in Figures 1a and $1 \mathrm{~b}$ respectively. Both systems appear to have a co-continuous morphology and as a result it was difficult to identify the individual polymers in the blends. Wang et al. [7] studied the morphology of a 50/50 w/w PP/LLDPE blend and reported a co-continuous two phase structure that could be broken down into an island-like structure by manual deformation. Zhang et al. [4] and Liang et al. [27] used two-dimensional wide-angle $\mathrm{X}$-ray scattering to

b)

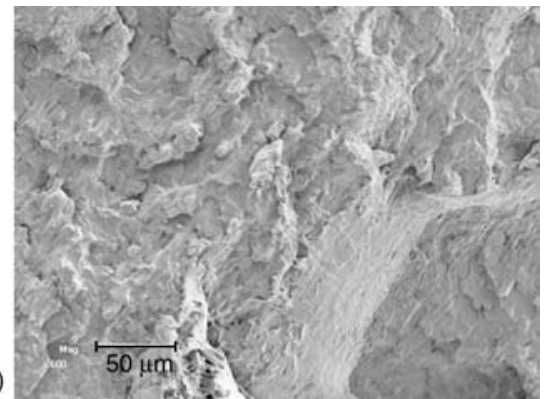

Figure 1. SEM photos of the fracture surfaces of (a) 50/50 w/w PP/LLDPE and (b) 50/50 w/w MAPP/LLDPE (600x magnification) 

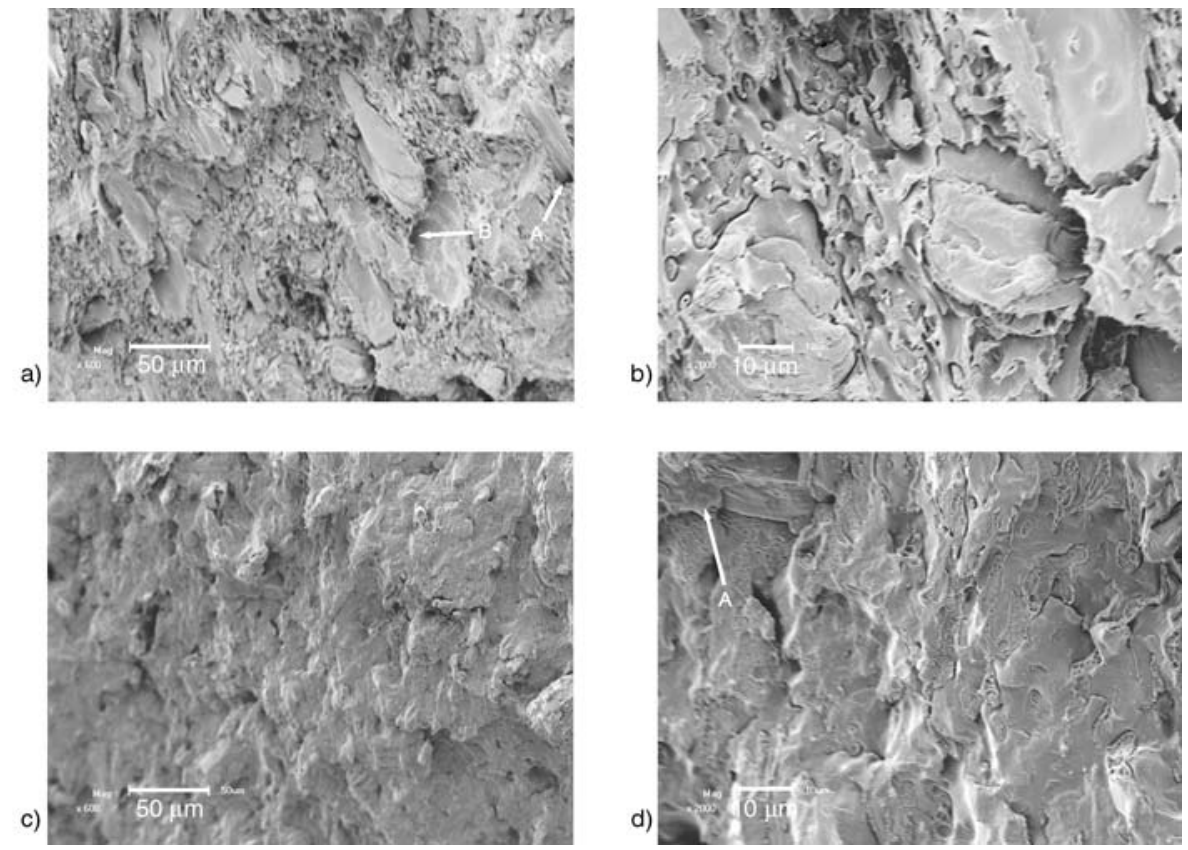

Figure 2. SEM photos of the fracture surfaces of (a) 40/40/20 w/w PP/LLDPE/WP (600× magnification);

(b) 40/40/20 w/w PP/LLDPE/WP (2000× magnification); (c) 40/40/20 w/w MAPP/LLDPE/WP (600× magnification); (d) 40/40/20 w/w MAPP/LLDPE/WP (2000× magnification)

study the morphology and interphase structure of an LLDPE/PP blend. They reported that no cross orientation was observed when PP and LLDPE were blended, and this finding was supported by the lack of change in the orientation of LLDPE even in the presence of PP fibres. Figure 1b shows a much smoother fracture surface, which seems to indicate better interfacial adhesion between MAPP and LLDPE.

The SEM photos of the 40/40/20 w/w PP/LLDPE/ WP blend composite (Figures $2 a$ and $2 b$ ) show cavities around the WP particles (A), as well as fibre pull-out (B). This indicates a fairly weak interaction between the fibre and the matrix. However, the macroscopic surface structure of the sample looks smoother than that of the PP/LLDPE blend (Figure 1). This may be the result of some affinity between the WP and LLDPE (see discussion of DSC results below). Some authors observed the same for the PP/NR/LLDPE ternary blend which was more homogeneous and had a finer disperse phase particle diameter than the PP/NR binary blend, due to the preference of natural rubber for LLDPE [26].

The SEM photos of the 40/40/20 w/w MAPP/ LLDPE/WP composite (Figures $2 \mathrm{c}$ and 2d) do not show the highly porous morphology, fibre pull-out and lack of intimate contact between the matrix and fibres, as were observed for the $40 / 40 / 20 \mathrm{w} / \mathrm{w}$
PP/LLDPE/WP composite (Figures $2 \mathrm{a}$ and $2 \mathrm{~b}$ ). The higher magnification photo in Figure $2 \mathrm{~d}$ shows that WP (indicated by A) seems to be in contact with both MAPP and LLDPE, but that it has more contact with one polymer than with the other one. This polymer is likely to be MAPP, due to its maleic anhydride functional groups that will react/ interact with the $-\mathrm{OH}$ groups on WP. Since WP seems to have a fairly good interaction with both LLDPE and MAPP, the composite structure should be less porous and the fractured surface smoother at first glance.

\subsection{Differential scanning calorimetry (DSC)}

The DSC heating curves of the PP/LLDPE and MAPP/LLDPE systems are presented in Figures 3 and 4 . The LLDPE endothermic melting peak is at $127^{\circ} \mathrm{C}$, while PP and MAPP both melt around $162^{\circ} \mathrm{C}$. The PP/LLDPE and the MAPP/LLDPE blends both show two peaks corresponding to the melting points of the two polymers. The DSC curve of the MAPP/LLDPE blend in Figure 4 shows two small endothermic peaks between the melting peaks of LLDPE and MAPP, while there are no intermediate peaks between those of PP and LLDPE in the PP/LLDPE blend (Figure 3). This indicates that there is probable formation of cocrystallites of the higher melting fraction of 


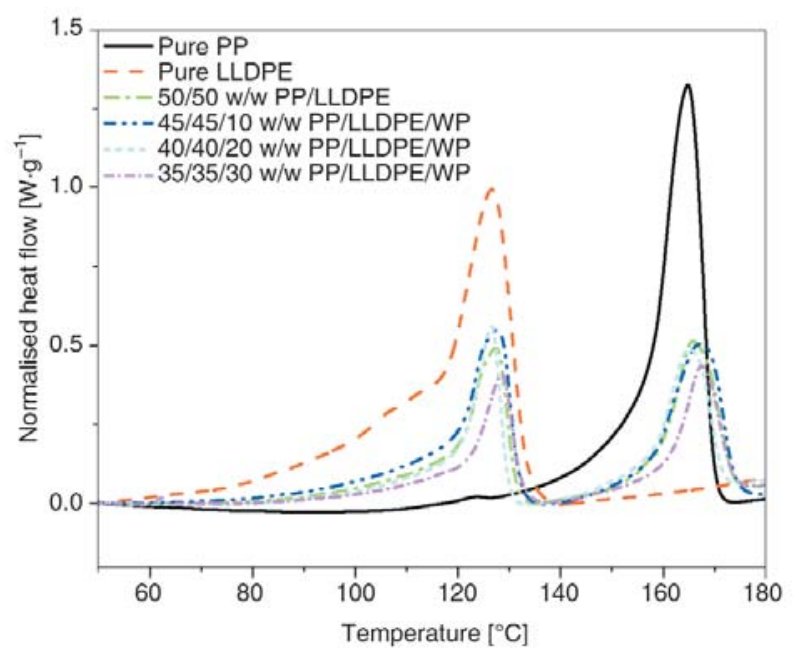

Figure 3. DSC heating curves of PP, LLDPE, the PP/LLDPE blend, and the PP/LLDPE/WP blend composites

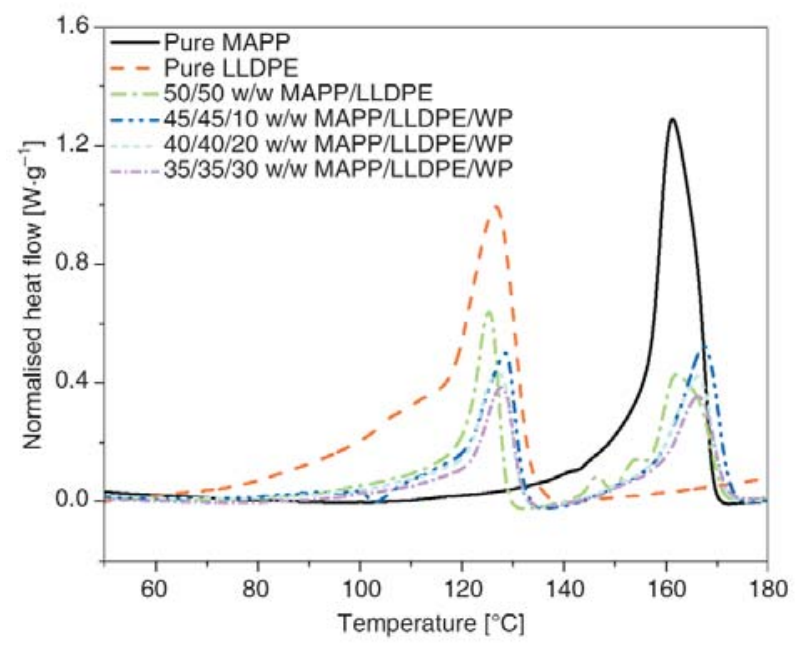

Figure 4. DSC heating curves of MAPP, LLDPE, the MAPP/LLDPE blend, and the MAPP/LLDPE/ WP blend composites
LLDPE and the lower melting fraction of MAPP. Fonseca and Harrison [28] investigated co-crystallinity in LDPE/HDPE blends using DSC and a co-crystal melting peak was observed at an intermediate temperature between those of LDPE and HDPE. The DSC data presented a melting-recrystallization-melting phenomenon. They concluded that the co-crystals were the result of crystallites melting, recrystallizing and melting again during the heating cycle of the DSC.

Similar blends were studied by Xu et al. [25] who reported that co-crystals can occur in two forms: firstly the linear parts of LDPE may be incorporated in the HDPE crystals; secondly the co-crystals may segregate from both the HDPE and LDPE and exist as a separate part, showing a third intermediate melting peak between the melting peaks of the two pure polymers.

The enthalpy values of the two components in the blends are shown in Table 1. The observed enthalpy values $\left(\Delta H^{o b s}\right)$ of both LLDPE and PP in the 50/50 w/w PP/LLDPE blend are the same as the calculated values $\left(\Delta H^{\text {calc }}\right)$ that were calculated taking into account the fractions of the respective polymers in the blends and assuming that the blending did not change the crystallization behaviour of the respective polymers. This indicates that blending did not significantly change the crystallization characteristics of the two polymers. The presence of WP particles slightly affected the LLDPE crystallization behaviour, while that of PP was not affected by the presence of WP. This is supported by the fact that the $\Delta H_{o b s}>\Delta H_{\text {calc }}$ in LLDPE while the differences between these values in PP are insignificant.

Table 1. DSC melting data for all the investigated samples

\begin{tabular}{|c|c|c|c|c|c|c|}
\hline & \multicolumn{2}{|c|}{$\mathbf{T}^{\text {Peak }}\left[{ }^{\circ} \mathbf{C}\right]$} & \multicolumn{2}{c|}{$\Delta \mathbf{H}^{\text {obs }}\left[\mathbf{J \cdot g} \mathbf{g}^{-1}\right]$} & \multicolumn{2}{c|}{$\Delta \mathbf{H}^{\text {calc }}\left[\mathbf{J}^{-\mathbf{- 1}}\right]$} \\
\hline PP/LLDPE/WP [w/w] & LLDPE & PP & LLDPE & PP & LLDPE & PP \\
\hline $100 / 0 / 0$ & - & $165.4 \pm 4.1$ & - & $79.3 \pm 3.8$ & - & $79.3 \pm 3.8$ \\
\hline $0 / 100 / 0$ & $127.4 \pm 2.3$ & - & $87.7 \pm 1.9$ & - & $87.7 \pm 1.9$ & - \\
\hline $50 / 50 / 0$ & $128.1 \pm 3.1$ & $165.5 \pm 2.1$ & $44.2 \pm 1.3$ & $38.9 \pm 1.7$ & $43.9 \pm 2.3$ & $39.6 \pm 2.5$ \\
\hline $45 / 45 / 10$ & $127.3 \pm 4.3$ & $168.4 \pm 2.9$ & $42.2 \pm 2.8$ & $34.6 \pm 1.5$ & $39.5 \pm 1.4$ & $35.7 \pm 2.6$ \\
\hline $40 / 40 / 20$ & $127.5 \pm 3.8$ & $165.3 \pm 1.9$ & $37.3 \pm 2.1$ & $30.7 \pm 1.8$ & $35.1 \pm 1.5$ & $31.7 \pm 3.2$ \\
\hline $35 / 35 / 30$ & $128.4 \pm 2.1$ & $167.4 \pm 3.4$ & $32.9 \pm 0.5$ & $26.9 \pm 1.5$ & $30.7 \pm 1.8$ & $27.7 \pm 2.1$ \\
\hline MAPP/LLDPE/WP [w/w] & & & & & & \\
\hline $100 / 0 / 0$ & - & $161.0 \pm 4.1$ & - & $75.3 \pm 3.8$ & - & $75.3 \pm 3.8$ \\
\hline $0 / 100 / 0$ & $127.4 \pm 2.3$ & - & $87.7 \pm 1.9$ & - & $87.7 \pm 1.9$ & - \\
\hline $50 / 50 / 0$ & $127.1 \pm 2.8$ & $162.3 \pm 2.3$ & $41.6 \pm 0.9$ & $24.8 \pm 1.3$ & $43.9 \pm 2.1$ & $37.7 \pm 1.7$ \\
\hline $45 / 45 / 10$ & $128.5 \pm 3.3$ & $167.5 \pm 2.5$ & $38.4 \pm 0.8$ & $22.7 \pm 1.6$ & $39.5 \pm 1.8$ & $33.9 \pm 1.6$ \\
\hline $40 / 40 / 20$ & $127.2 \pm 1.9$ & $163.4 \pm 3.2$ & $33.8 \pm 1.1$ & $19.8 \pm 1.9$ & $35.1 \pm 1.2$ & $30.1 \pm 1.1$ \\
\hline $35 / 35 / 30$ & $128.5 \pm 2.4$ & $167.6 \pm 3.4$ & $28.1 \pm 0.5$ & $17.4 \pm 0.8$ & $30.7 \pm 1.5$ & $26.3 \pm 1.7$ \\
\hline
\end{tabular}

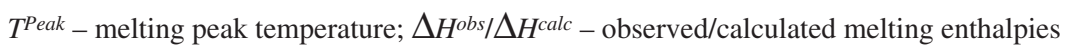


There are differences between the $\Delta H^{o b s}$ and the $\Delta H^{\text {calc }}$ values of LLDPE and MAPP in the MAPP/ LLDPE blend (Table 1), which indicates that the crystallization behaviour of both these polymers is influenced by the presence of the other polymer in the blend. It seems as if the MAPP crystallization is influenced more by the presence of LLDPE than vice versa. The absence of the additional small peaks in all the heating curves of the MAPP/ LLDPE/WP blend composites shows that the MAPP probably crystallized on the WP surfaces, which would reduce the co-crystallization of MAPP and LLDPE.

The DSC cooling curves of the PP/LLDPE systems are shown in Figure 5. The LLDPE and PP crystallization peak temperatures are at 105 and $110^{\circ} \mathrm{C}$ respectively. The 50/50 w/w PP/LLDPE blend shows one crystallization peak at $107^{\circ} \mathrm{C}$, despite the immiscibility of the two components. The single crystallization peak for the blend is due to the very close crystallization temperatures of the individual polymers. The most probable reason for the formation of a single crystallization peak is the fact that the polymer blend was cooled at a relatively high rate of $10^{\circ} \mathrm{C} \cdot \mathrm{min}^{-1}$. The crystallization of $\mathrm{PP} /$ HDPE blend-based nanocomposites was studied by Chiu et al. [29], who reported a single crystallization exotherm when cooled at $10^{\circ} \mathrm{C} \cdot \mathrm{min}^{-1}$. Faster cooling rates allow less time for reorganization and therefore prohibit the diffusion and proper separation of one polymer from the other [28]. Li et al. [30] studied the miscibility and isothermal crystallization of polypropylene in polyethylene melts,

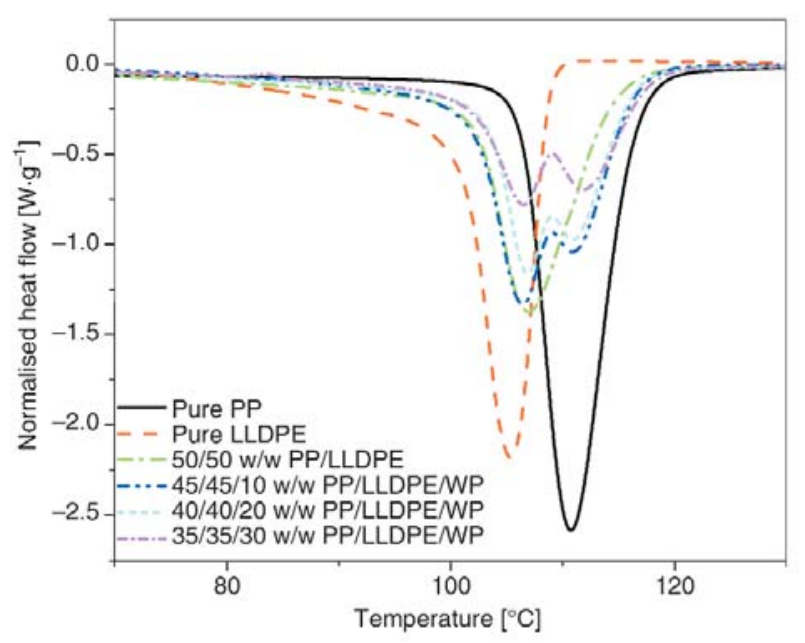

Figure 5. DSC cooling curves of PP, LLDPE, the PP/LLDPE blend, and the PP/LLDPE/WP blend composites and reported that the crystallization temperature of PP is close to that of HDPE so that the two peaks overlap. The PP/HDPE (20/80) blend showed only a single peak between the crystallization temperatures of PP and HDPE, which was broader than the crystallization peaks of pure PP and HDPE. Similar results were reported for the PP/LLDPE (20/80) blend, but in this system a new peak, which has been identified as the crystallization of PP, appeared at $88^{\circ} \mathrm{C}$. It was explained as the dissolution of the PP in the LLDPE in the molten state [30]. The appearance of the lower PP crystallization peak is explained as a delay in the PP crystallization because the concentration of PP in the PE-rich matrix is too low to form nuclei, and hence the crystallization of PP is delayed. During the crystallization of LLDPE, the concentration of PP in the melt increases to the point where PP is able to crystallize at a lower temperature and the crystalline LLDPE act as nuclei for the crystallization of PP. It was further observed that the intensity of the peak at $88^{\circ} \mathrm{C}$ decreased until the peak disappeared and only one crystallization peak for the PP/LLDPE blend was observed. This is due to the simultaneous crystallization of PP and LLDPE, and is in line with our own observations on the crystallization behaviour of this blend. The presence of WP promotes the separate crystallization of the two polymers. There was a small increase in the crystallization temperature of the LLDPE, while that of PP remained constant in the presence of WP. It seems as if there is some interaction between LLDPE and WP (see SEM discussion above) which retards the LLDPE crystallization, while the crystallization of PP is not affected by the presence of WP. This observation indicates that WP preferably locates itself in LLDPE and retards its crystallization, allowing PP to crystallize first.

The crystallization peaks of pure LLDPE and pure MAPP are at 105 and $110^{\circ} \mathrm{C}$ respectively (Figure 6). Considering the heating rate and the closeness of the crystallization, it would be expected that the MAPP/LLDPE blend will show a single crystallization peak as was observed for the PP/LLDPE blend. However, in this case two overlapping crystallization peaks at 107 and $110^{\circ} \mathrm{C}$ are observed. A possible explanation for the separate crystallization peaks in this blend is that MAPP and LLDPE are less miscible in the melt, and that MAPP therefore started crystallizing at its normal crystallization 


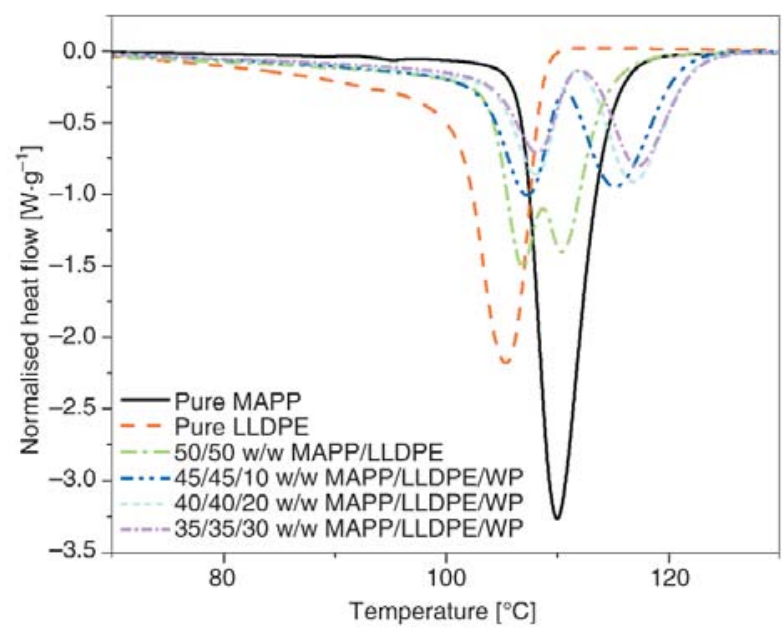

Figure 6. DSC cooling curves of MAPP, LLDPE, the MAPP/LLDPE blend, and the MAPP/LLDPE/ WP blend composites

temperature. However, it seems as if the crystallized MAPP acted as nuclei for the crystallization of LLDPE, and if there was some co-crystallization of some MAPP and LLDPE fractions (see discussion of DSC heating curves). The co-crystalline material probably contained the higher melting fraction of LLDPE and the lower melting fraction of MAPP. Fonseca and Harrison [28] made similar observations, and explained the interaction between the two components as being due to the formation of co-crystallites from the higher temperature portion of LDPE and the lower temperature tail of HDPE. Chiu et al. [29] also reported two crystallization isotherms of a PP/HDPE blend in the presence of MAPP.

The crystallization temperatures of both LLDPE and MAPP increased in the presence of WP. Since there should be stronger interaction between WP and MAPP [31], the WP probably acts as a nucleating agent for MAPP crystallization, so that the MAPP starts crystallizing at a higher temperature. Both the WP and the crystallized MAPP will nucleate LLDPE crystallization, so that the LLDPE also starts crystallizing at a higher temperature. This to some extent explains the SEM observations that both polymers are in contact with WP, but that more of the one polymer (probably MAPP) seems to be in contact with the WP.

\subsection{Mechanical properties}

The tensile modulus $(E)$, elongation at break $\left(\varepsilon_{b}\right)$ and tensile strength at break $\left(\sigma_{b}\right)$ of the polymers, blends and blend composites are shown in Table 2 . All the mechanical property values of the pure polymers have the trend: PP $>$ MAPP $>$ LLDPE. However, the MAPP/LLDPE blend has better mechanical properties than PP/LLDPE. Morphology is a major determinant of the properties of heterogeneous polymer blends. Weak adhesion would result in poor mechanical properties in the blends. The inferior properties of the PP/LLDPE blend can be confirmed from the SEM photo of the blend (Figure 1a), which shows incompatibility. The voids observed in this blend will act as defects when mechanical stress is applied. The MAPP/ LLDPE blend shows almost no voids (Figure 1b) that should give rise to better mechanical properties.

A continuous increase in Young's modulus in the composites of both types of blends indicates the ability of the composites to resist deformation as more fibre is added. This is due the stiff characteristic of the fibres. The Young's modulus of all the PP/LLDPE/WP blend composites is higher than those of the comparable MAPP/LLDPE/WP blend composites. This is understandable considering that pure PP is rigid and has a higher modulus than MAPP.

The blending of MAPP and LLDPE resulted in a blend with elongation at break higher than those of the individual polymers. However, the elongation at break of the PP/LLDPE blend is lower than the two individual polymers, and is related to the incompatibility of the two polymers. The increase

Table 2. Tensile properties of MAPP/LLDPE/WP and PP/LLDPE/WP blend composites

\begin{tabular}{|c|c|c|c|c|c|c|c|}
\hline & $\mathbf{E} \pm \mathbf{s E}[\mathbf{M P a}]$ & $\boldsymbol{\varepsilon}_{\mathbf{b}} \pm \mathbf{s} \boldsymbol{\varepsilon}_{\mathbf{b}}[\%]$ & $\sigma_{\mathbf{b}} \pm \mathbf{s} \boldsymbol{\sigma}_{\mathbf{b}}[\mathbf{M P a}]$ & $\mathbf{E} \pm \mathbf{s E}[\mathbf{M P a}]$ & $\boldsymbol{\varepsilon}_{\mathbf{b}} \pm \mathbf{s} \varepsilon_{\mathbf{b}}[\%]$ & $\boldsymbol{\sigma}_{\mathbf{b}} \pm \mathbf{s} \boldsymbol{\sigma}_{\mathbf{b}}[\mathbf{M P a}]$ \\
\hline & \multicolumn{3}{|c|}{$\mathbf{M A P P} / \mathbf{L D P P E} / \mathbf{W P}[\mathbf{w} / \mathbf{w}]$} & \multicolumn{3}{|c|}{$\mathbf{P P / L L D P E} / \mathbf{W P}[\mathbf{w} / \mathbf{w}]$} \\
\hline $100 / 0 / 0$ & $377.7 \pm 20.3$ & $13.3 \pm 1.2$ & $24.4 \pm 0.5$ & $498.5 \pm 13.5$ & $26.7 \pm 2.5$ & $29.9 \pm 1.3$ \\
\hline $0 / 100 / 0$ & $323.2 \pm 17.6$ & $10.5 \pm 1.4$ & $15.3 \pm 1.6$ & $323.2 \pm 17.6$ & $10.5 \pm 1.4$ & $15.3 \pm 1.6$ \\
\hline $50 / 50 / 0$ & $770.2 \pm 19.6$ & $18.9 \pm 2.4$ & $18.7 \pm 1.5$ & $612.2 \pm 11.2$ & $10.7 \pm 0.9$ & $17.6 \pm 0.6$ \\
\hline $45 / 45 / 10$ & $784.4 \pm 22.5$ & $3.8 \pm 1.4$ & $15.8 \pm 1.7$ & $850.9 \pm 29.8$ & $3.2 \pm 0.2$ & $14.8 \pm 0.2$ \\
\hline $40 / 40 / 20$ & $794.5 \pm 35.9$ & $3.7 \pm 0.2$ & $10.6 \pm 1.4$ & $887.8 \pm 27.2$ & $2.8 \pm 0.2$ & $8.4 \pm 1.1$ \\
\hline $35 / 35 / 30$ & $878.7 \pm 43.6$ & $2.5 \pm 0.2$ & $10.3 \pm 1.4$ & $946.7 \pm 30.9$ & $1.9 \pm 0.1$ & $5.7 \pm 0.4$ \\
\hline
\end{tabular}

$E$ - tensile modulus, $\varepsilon_{b}$ - elongation at break, $\sigma_{b}$-tensile strength 
in the elongation at break of the MAPP/LLDPE blend is related to an interaction that leads to the formation of the co-crystallites between MAPP and LLDPE. The elongation at break of the MAPP/ LLDPE/WP blend composites is higher than that of the comparable PP/LLDPE/WP blend composites, which is in line with the observations on the respective blends.

Pure PP shows better stress at break values than pure MAPP (Table 2), but the difference is not significant, and therefore any differences between the stress at break values of the blends and blend composites may be explained in terms of reduced or improved interactions between the different components in the samples. It is interesting that the MAPP/LLDPE blend shows a higher average stress at break than the PP/LLDPE blend, despite the higher stress at break for pure PP. This is in line with the conclusion from the SEM observations that there seems to be stronger interaction between MAPP and LLDPE. For both MAPP/LLDPE and PP/LLDPE the stress at break values are between those of pure LLDPE and pure MAPP or PP, and this indicates (at least partial) co-continuity between the LLDPE and MAPP/PP phases. The PP/LLDPE/WP composites show a decrease in stress at break with increasing fibre content, which is the result of poor interaction between WP and the polymers in the blend matrix, and of the fibres acting as defect centres for crack propagation. The MAPP/LLDPE/WP composites also show lower stress at break values than the individual polymers or the blend, but the vales are generally higher than the respective values for the PP/LLDPE/WP composites. The better interaction between MAPP and WP would cause better stress transfer, but not significant enough to maintain or even improve the tensile strength at break of the composites compared to the pure polymers or the blend.

\subsection{Dynamic mechanical analysis (DMA)}

The storage modulus is closely related to the load carrying capacity of the material [32]. The storage modulus curves of PP, MAPP, LLDPE, the PP/ LLDPE and MAPP/LLDPE blends, and their 10\% WP containing composites are presented in Figure 7. The storage modulus values of PP and MAPP are very close to each over the whole temperature range. This indicates that the stiffness of PP and

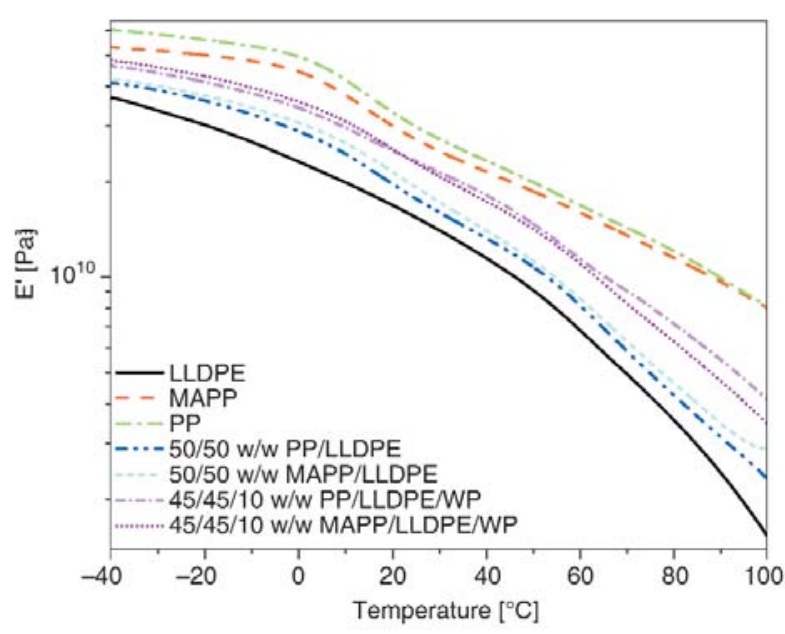

Figure 7. DMA storage modulus curves of PP, MAPP, LLDPE, their blends and their 10\% WP containing blend composites

MAPP is similar, and that maleic anhydride grafting did not significantly change this property. A continuous decrease in the storage modulus of MAPP and PP with increasing temperature is observed, with a faster decrease around the glass transition temperature $\left(16^{\circ} \mathrm{C}\right)$. The storage modulus of LLDPE is lower than those of MAPP and PP over the whole temperature range, and the difference becomes more significant at higher temperatures. The storage moduli of the PP/LLDPE and MAPP/LLDPE blends are only slightly higher than those of LLDPE, but observably lower than those of PP and MAPP. However, the storage moduli of the MAPP/LLDPE blend are slightly higher than those of the PP/ LLDPE blend, probably due to some interaction between MAPP and LLDPE. The PP/LLDPE/WP and MAPP/LLDPE/WP samples have almost the same storage moduli, but higher than those of the blend. This is due to the stiffening effect of the WP. The storage modulus results of the different samples are not in line with the tensile modulus results (Table 2). As already discussed, the tensile moduli of the blends and 10\% WP containing composites are observably higher than those of the pure polymers. The reason for this is probably that dynamic mechanical analysis involves only weak stresses, and that the adhesion (or lack of adhesion) between the filler and matrix has a different influence on the storage modulus compared to the tensile modulus [32].

The mechanical loss/damping factor is the ratio of loss modulus to storage modulus and is represented as $\tan \delta$. The damping properties of the material 


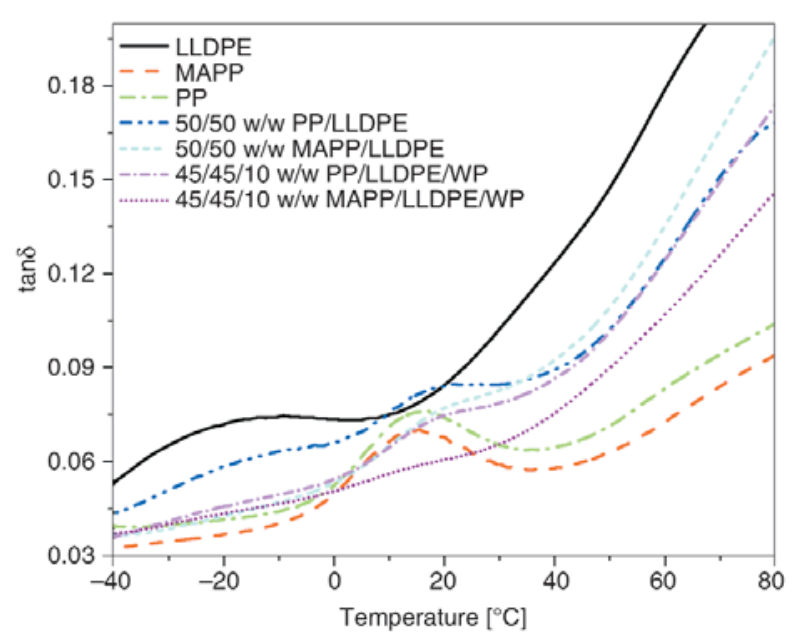

Figure 8. Loss factor curves of PP, MAPP, LLDPE, their blends and their 10\% WP containing blend composites

give the balance between the elastic phase and the viscous phase in a polymeric structure. The damping behaviour of a polymer blend is governed by the mechanical relaxation of the two blended polymers, the content used and the interface between the two polymers. In composites, the damping transitions are characterized by the mechanical relaxation of the polymer matrix and the filler, the content used and the filler size or length [33, 34]. Figure 8 shows a comparison of $\tan \delta$ as a function of temperature of PP, MAPP, LLDPE, the PP/ LLDPE and MAPP/LLDPE blends, and their 10\% WP containing blend composites. Both PP and MAPP have a $\beta$-transition peak at about $16^{\circ} \mathrm{C}$. This transition corresponds to the glass transition $\left(T_{g}\right)$ of the amorphous region in PP and MAPP [24, 33]. LLDPE has a $\beta$-transition at $-15^{\circ} \mathrm{C}$, which is related to the movement of polymer side or short chains [35]. The damping peaks in the blend and the blend composites show a decrease in intensity compared to the pure polymers. With the presence of other components in the polymer, the amount of polymer in a blend or composite decreases and the polymer structure becomes partially loosened so as to accommodate the other component. The decrease in the quantity of matrix used and the loosening of the polymer structure lead to a reduction in the intensity of the damping peak [33].

The PP/LLDPE blend shows peaks related to the PP and the LLDPE transitions, and the presence of both these transitions indicate the incompatibility of the two polymers [35]. In the MAPP/LLDPE blend, the LLDPE transition has disappeared, whereas the MAPP glass transition has broadened and has slightly shifted to a higher temperature of $20^{\circ} \mathrm{C}$. This indicates that the polymer chain mobility has been restricted due to the partial miscibility of and/or the interfacial interaction between MAPP and LLDPE.

In the PP/LLDPE/WP composites the transition related to LLDPE disappears, while the PP transition is still visible at the same temperature as in the PP/LLDPE blend. This may be due to the stronger interaction between LLDPE and WP. The MAPP glass transition, which is clearly visible for the MAPP/LLDPE blend, disappears when WP is present in the MAPP/LLDPE blend. This indicates that WP influences the MAPP chain mobility due to the interaction between WP and MAPP. The damping factor values of the MAPP containing composites are generally lower than those of the PP containing composites. This indicates that the energy dissipation of the MAPP containing systems is lower than that of the PP containing systems. Since energy dissipation occurs at the interface, the better interfacial adhesion in the MAPP containing systems may be responsible for the lower dissipation of energy. Similar results were reported by Kim et al. [34].

\subsection{Thermogravimetric analysis (TGA)}

The TGA curves of the different samples are shown in Figures 9 and 10. PP, LLDPE and the PP/LLDPE blend all have a single degradation step. PP starts degrading at $330^{\circ} \mathrm{C}$ while LLDPE starts degrading at $400^{\circ} \mathrm{C}$. The single degradation step for both polymers confirms that the polymers are composed

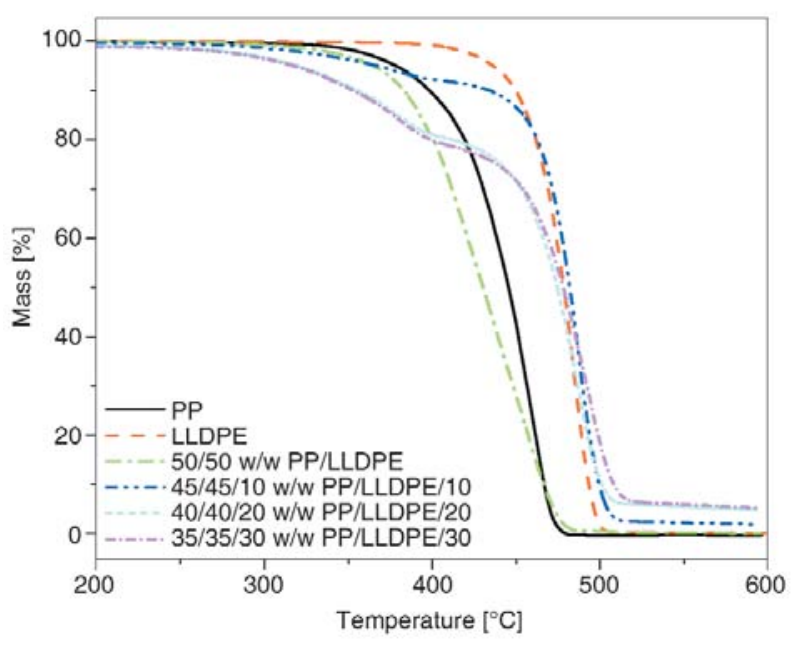

Figure 9. TGA curves of PP, LLDPE, the PP/LLDPE blend, and the PP/LLDPE/WP blend composites 
of the carbon-carbon bonds in the main chain, thereby allowing a temperature increase to promote random scission, with associated thermal degradation and thermal depolymerization taking place at a weak part of the polymer main chain [34]. Above 450 and $500^{\circ} \mathrm{C}$, for PP and LLDPE respectively, no residue or char was visible. The PP/LLDPE blend starts degrading at $310^{\circ} \mathrm{C}$, despite the fact that the two individual polymers are both degrading at higher temperatures, and leaves no residue. Mourad [36] studied the thermo-mechanical characteristics of thermally aged polyethylene/polypropylene blends and reported that the 50/50 w/w PP/PE blend had a lower degradation temperature than the pure polymers and the $\mathrm{PP} / \mathrm{PE}$ blends of other ratios. The decrease in the thermal stability of the PP/ LLDPE blend is probably due to the presence of voids in the blend (Figure 1a) which trap oxygen that will promote the degradation process and cause a decrease in thermal stability.

The PP/LLDPE/WP blend composites have two degradation steps. The first step corresponds to the degradation of WP. The depolymerization of hemicelluse occurs between 150 and $350^{\circ} \mathrm{C}$, the random cleavage of glycosidic linkages of cellulose between 275 and $350^{\circ} \mathrm{C}$, and the degradation of lignin between 250 and $480^{\circ} \mathrm{C}$. During the degradation of these WP constituents, volatile materials such as $\mathrm{CO}$ and $\mathrm{CH}_{4}$, and residue/char are formed [36]. The second step corresponds to the degradation of the polymer blend matrix. When $30 \%$ of WP is used, the residue at $515^{\circ} \mathrm{C}$ is about $6.5 \%$. The char formation caused a diffusion effect, which inhibited the emission of the gaseous degradation products, showing an apparent increase in the thermal stability of the composite matrix (Figure 7). Chiu et al. [30] reported that the inclusion of a nano-filler in PP/HDPE enhanced the blend's thermal stability. Similar findings were reported by Duquesne et al. [37] and Peeterbroeck et al. [38] while investigating EVA/nanoclay systems. Dikobe and Luyt [24] studied PP/EVA/WP blend composites and reported an increase in the thermal stability of the PP/EVA blend in the presence of WP.

MAPP is more thermally stable than PP, and also has one degradation step which starts at $340^{\circ} \mathrm{C}$ (Figure 10). The MAPP/LLDPE blend is more thermally stable (starts degrading at $410^{\circ} \mathrm{C}$ ) than the individual polymers. The improved thermal stabil-

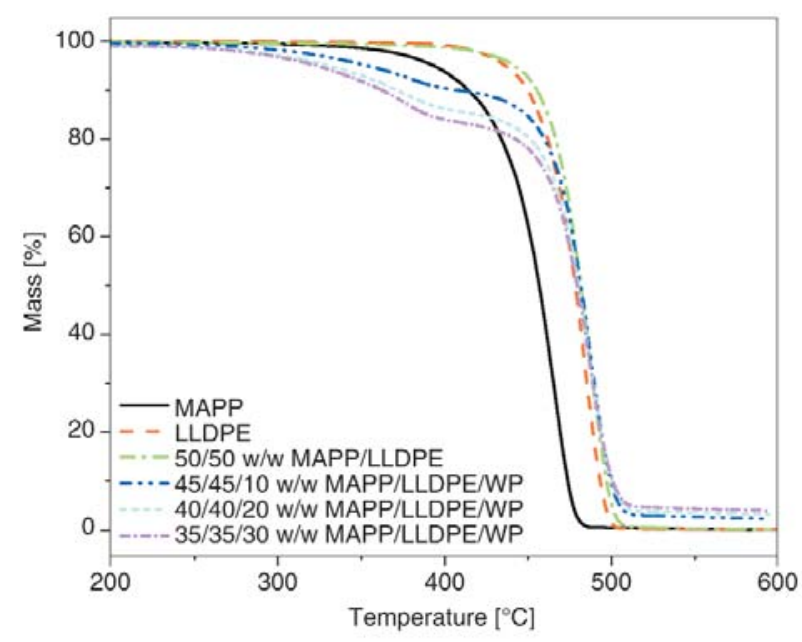

Figure 10. TGA curves of MAPP, LLDPE, the MAPP/ LLDPE blend, and the MAPP/LLDPE/WP blend composites

ity of the MAPP containing blend was due to limited co-crystallization that occurred between MAPP and LLDPE. The resulting polymer blend has an intact structure with fewer voids and hence only a small ability to trap air that will promote degradation. Chiu et al. [29] reported that the improvement in thermal stability of smooth/finer surfaced PP/HDPE/PP-MA was due to oxygen and heat permeability reduction in the blend matrix during the heating process. Another reason may be that stronger interaction between the MAPP functional groups and the gaseous degradation products retarded the diffusion of these products out of the sample, so that mass loss was only observed at higher temperatures, indicating an apparent higher thermal stability.

The presence of WP in the MAPP/LLDPE blend also gives rise to two degradation steps. There is a delay in the thermal degradation of WP in the MAPP/LLDPE/WP blend composites, which may also have been the result of a diffusion effect caused by interaction between the gaseous degradation products of WP and the functional groups on MAPP. Although there is an observable increase in the decomposition temperature of the first step, an insignificant change in the decomposition temperature of the second step is observed. Kim et al. [17] studied the effect of MAPP and HDPE-MA compatibilizers on rice husk flour (RHF)/polymer composites. They reported that in both RHF-filled PP and RHF-filled LDPE composites, the first and second degradation temperatures slightly shifted to 
higher temperatures as compared to the non-treated composites and slightly increased with increasing MAPP and HDPE-MA content.

\section{Conclusions}

Morphology is an important determinant of the properties of heterogeneous polymer blends and their composites. The MAPP/LLDPE blend and the MAPP/LLDPE/WP blend composites show better mechanical properties than the PP/LLDPE blend and the PP/LLDPE/WP blend composites, because of apparent stronger interaction between the different components of the blend and composites. The SEM photos of the MAPP/LLDPE blend show a smoother fracture surface than the PP/LLDPE blends, which may be an indication of better interaction between MAPP and LLDPE. The DSC heating curves show stronger interaction between and probable co-crystallization of MAPP and LLDPE in the MAPP/LLDPE blend. This interactive cocrystallization seems to be absent when WP is present in this blend, probably because there is a stronger interaction between MAPP and WP which leads to the MAPP preferably crystallizing on the WP surfaces. The WP also seems to locate itself in both polymers, although it has a stronger affinity for MAPP. These interactions seem to be absent between PP and LLDPE in the PP/LLDPE blend and the PP/LLDPE/WP blend composites. The DSC results indicate some interaction between WP and LLDPE in the PP/LLDPE/WP composites, but this seems to be insignificant compared to the interaction between WP and MAPP in the MAPP/ LLDPE/WP composites. These interactions, or the lack thereof, are reflected in the non-isothermal crystallization behaviour of the respective polymers in the different blends and composites, in their dynamic mechanical properties, and in the TGA results, where the PP/LLDPE blend is less thermally stable than the individual polymers, but the MAPP/LLDPE blend is more thermally stable than the individual polymers. The MAPP/LLDPE/WP composites are also more thermally stable than the PP/LLDPE/WP composites due to stronger interactions between the different components.

\section{Acknowledgements}

The National Research Foundation in South Africa (GUN 62017) and the University of the Free State are acknowledged for financial support of the project.

\section{References}

[1] Li Z-H., Yang W., Xie B-H., Yang S. Y., Yang M-B., Feng J-M., Huang R.: Effects of compatibilization on the essential work of fracture parameters of in situ microfiber reinforced poly(ethylene terephtahalate)/ polyethylene blend. Materials Research Bulletin, 38, 1867-1878 (2003).

DOI: 10.1016/j.materresbull.2003.07.007

[2] Chen J-H., Zhong J-C., Cai Y-H., Su W-B., Yang YB.: Morphology and thermal properties in the binary blends of poly(propylene-co-ethylene) copolymer and isotactic polypropylene with polyethylene. Polymer, 48, 2946-2957 (2007).

DOI: 10.1016/j.polymer.2007.03.037

[3] Menyhárd A., Varga J.: The effect of compatibilizers on the crystallization, melting and polymorphic composition of $\beta$-nucleated isotactic polypropylene and polyamides 6 blends. European Polymer Journal, 42, 3257-3268 (2006). DOI: $10.1016 /$ j.eurpolymj.2006.09.003

[4] Zhang X. M., Ajji A.: Oriented structure of PP/LLDPE multilayer and blends films. Polymer, 46, 3385-3393 (2005).

DOI: 10.1016/j.polymer.2005.03.004

[5] Nitta K-H., Shin Y-W., Hashiguchi H., Tanimoto S., Terano M.: Morphology and mechanical properties in the binary blends of isotactic polypropylene and novel propylene-co-olefin random copolymers with isotactic propylene sequence. 1. Ethylene-propylene copolymers. Polymer, 46, 965-975 (2005). DOI: $10.1016 /$ j.polymer.2004.11.033

[6] Nedkov T., Lednický F.: Morphologies of polyethylene-ethylene/propylene/diene monomer particles in polypropylene-rich polyolefin blends: Flake structure. Journal of Applied Polymer Science, 90, 3087-3092 (2003). DOI: $10.1002 / a p p .13050$

[7] Wang Y., Zou H., Fu Q., Zhang G., Shen K., Thomann R.: Shear-induced morphological change in PP/LLDPE blend. Macromolecular Rapid Communications, 23, 749-752 (2002).

DOI: 10.1002/1521-3927(20020901)23:13<749::AIDMARC749>3.0.CO;2-X

[8] Huerta-Martínez B. M., Ramirez-Vargas E., MedellínRodrequez F. J., Garcia R. C.: Compatibility mechanisms between EVA and complex impact heterophasic PP-EPx copolymers as a function of EP content. European Polymer Journal, 41, 519-525 (2005). DOI: $\underline{10.1016 / \text { j.eurpolymj.2004.10.021 }}$ 
[9] González J., Albano C., Ichazo M., Díaz B.: Effects of coupling agents on mechanical and morphological behavior of the PP/HDPE blend with two different $\mathrm{CaCO}_{3}$. European Polymer Journal, 38, 2465-2475 (2002).

DOI: 10.1016/S0014-3057(02)00120-9

[10] Long Y., Shanks R. A., Stachurski Z. H.: Time dependent morphologies of immiscible polymer blends. Journal of Material Science Letters, 15, 610-612 (1996). DOI: $10.1007 / \mathrm{BF} 00579266$

[11] Albano C., Reyes J., Ichazo M., González J., Chipara M. I.: Influence of gamma irradiation on the thermal stability of blends with previously treated sisal fibre. Polymer Degradation and Stability, 73, 225-236 (2001).

DOI: $10.1016 / \mathrm{S} 0141-3910(01) 00036-2$

[12] Salemane M. G., Luyt A. S.: Thermal and mechanical properties of polypropylene-wood powder composites. Journal of Applied Polymer Science, 100, 41734180 (2006). DOI: 10.1002/app.23521

[13] Suarez J. C. M., Coutihno F. M. B., Sydentricker T. H.: SEM studies of tensile fracture surfaces of polypropylene-sawdust composites. Polymer Testing, 22, 819-824 (2003). DOI: $10.1016 / \mathrm{S} 0142-9418(03) 00017-5$

[14] Amash A., Zugenmaier P.: Morphology and properties of isotropic and oriented samples of cellulose fibre-polypropylene composites. Polymer, 41, 15891596 (2000). DOI: $10.1016 /$ S0032-3861(99)00273-6

[15] Bledzki A. K., Gassan J.: Composites reinforced with cellulose based fibres. Progress in Polymer Science, 24, 221-274 (1999).

DOI: $10.1016 /$ S0079-6700(98)00018-5

[16] Harper D., Wolcott M.: Interaction between coupling agent and lubricants in wood-polypropylene composites. Composites Part A: Applied Science and Manufacturing, 35, 385-394 (2004).

DOI: 10.1016/j.compositesa.2003.09.018

[17] Kim H-S., Lee B-H., Choi S-W., Kim S., Kim H-J., Yang H-S.: The effect of types of maleic anhydridegrafted polypropylene (MAPP) on the interfacial adhesion properties of bio-flour-filled polypropylene composites. Composites Part A: Applied Science and Manufacturing, 38, 1473-1482 (2007).

DOI: $10.1016 /$ j.compositesa.2007.01.004

[18] Premphet K., Horanont P.: Phase structure of ternary polypropylene/elastomer/filler composites: Effect of elastomer polarity. Polymer, 41, 9283-9290 (2000). DOI: 10.1016/S0032-3861(00)00303-7

[19] Albano C., González J., Ichazo M., Rosales C., Urbina de Navcarro C., Parra C.: Mechanical and morphological behavior of polyolefin blends in the presence of $\mathrm{CaCO}_{3}$. Composite Structures, 48, 49-58 (2000). DOI: $\underline{10.1016 / \mathrm{S} 0263-8223(99) 00072-0}$
[20] Ramos M. A., Berna M. S., Matheu J. P. V.: Effect of talc surface treatment on the mechanical properties of composites based on PP/LDPE blend matrices. Polymer Engineering and Science, 31, 245-252 (1991). DOI: $10.1002 /$ pen.760310407

[21] Gupta A. P., Saroop U. K. Verma M.: Studies of mechanical and thermal properties of polypropylene/ LLDPE-copolymer blends and its glass fiber compositions. Polymer-Plastics Technology and Engineering, 43, 937-950 (2004). DOI: $\underline{\text { 10.1081/PPT-120038071 }}$

[22] Ichazo M. N., Albano C., González J.: Behavior of polyolefins blends with acetylated sisal fiber. Polymer International, 49, 1409-1416 (2000).

DOI: $10.1002 / 1097-0126(200011) 49: 11<1409::$ AIDPI512>3.0.CO;2-T

[23] Espert A., Vilaplana F., Karlsson S.: Comparison of water absorption in natural cellulosic fibres from wood and one-year crops in polypropylene composites and its influence on their mechanical properties. Composites Part A: Applied Science and Manufacturing, 35, 1267-1276 (2004).

DOI: 10.1016/j.compositesa.2004.04.004

[24] Dikobe D. G., Luyt A. S.: Morphology and properties of polypropylene/ethylene vinyl acetate copolymer/ wood powder blend composites. Express Polymer Letters, 3, 190-199 (2009). DOI: $10.3144 /$ expresspolymlett.2009.24

[25] Xu J., Xu X., Chen L., Feng L., Chen W.: Effect of composition distribution on miscibility and co-crystallization phenomena in the blends of low density polyethylene with conventional and metallocene-based ethylene-butene copolymers. Polymer, 42, 3867-3874 (2001). DOI: $\underline{10.1016 / \mathrm{S} 0032-3861(00) 00756-4}$

[26] Hassan A., Wahit M. U., Chee C. Y.: Mechanical and morphological properties of PP/NR/LLDPE ternary blend- Effect of HVA-2. Polymer Testing, 22, 281290 (2003).

DOI: 10.1016/S0142-9418(02)00100-9

[27] Liang S., Wang K., Yang H., Zhang Q., Du R., Fu Q.: Crystal morphology and tensile properties of LLDPE containing PP fibers as obtained via dynamic packing injection molding. Polymer, 47, 7115-7122 (2006). DOI: $10.1016 /$ j.polymer.2006.08.021

[28] Fonseca C. A., Harrison I. R.: An investigation of cocrystallization in LDPE/HDPE blends using DSC and TREF. Thermochimica Acta, 313, 37-41 (1998). DOI: $10.1016 / \mathrm{S} 0040-6031(97) 00465-6$

[29] Chiu F-C., Yen H-Z., Lee C-E.: Characterization of PP/HDPE blend-based nanocomposites using different maleated polyolefins as compatibilizers. Polymer Testing, 29, 397-406 (2010). DOI: $\underline{10.1016 / j . p o l y m e r t e s t i n g .2010 .01 .004}$ 
[30] Li J., Shanks R. A., Olley R. H., Greenway G. R.: Miscibility and isothermal crystallisation of polypropylene in polyethylene melts. Polymer, 42, 7685-7694 (2001).

DOI: $10.1016 / \mathrm{S} 0032-3861(01) 00248-8$

[31] Dikobe D. G., Luyt A. S.: Morphology and thermal properties of maleic anhydride grafted polypropylene/ethylene-vinyl acetate copolymer/wood powder blend composites. Journal of Applied Polymer Science, 116, 3193-3201 (2010).

DOI: $10.1002 /$ app.31630

[32] Dufresne A., Dupeyre D., Paillet M.: Lignocellulosic flour-reinforced poly(hydroxybutyrate-co-valerate) composites. Journal of Applied Polymer Science, 87, 1302-1315 (2003).

DOI: 10.1002/app.11546

[33] Jayanarayan K., Thomas S., Joseph K.: Morphology, static and dynamic mechanical properties of in situ microfibrillar composites based on polypropylene/ poly(ethylene terephthalate) blends. Composites Part A: Applied Science and Manufacturing, 39, 164-175 (2008).

DOI: $\underline{10.1016 / \mathrm{j} . c o m p o s i t e s a .2007 .11 .008}$
[34] Kim H-S., Kim S., Kim H-J., Yang H-S.: Thermal properties of bio-flour-filled polyolefin composites with different compatibilizing agent type and content. Thermochimica Acta, 451, 181-188 (2006).

DOI: $10.1016 /$ j.tca.2006.09.013

[35] Dahlan H. M., Zaman M. D. K., Ibrahim A.: The morphology and thermal properties of liquid naturalrubber (LNR)-compatibilized 60/40 NR/LLDPE blends. Polymer Testing, 21, 905-911 (2002).

DOI: $10.1016 / \mathrm{S} 0142-9418(02) 00027-2$

[36] Mourad A-H. I.: Thermo-mechanical characteristics of thermally aged polyethylene/polypropylene blends. Materials and Design, 31, 918-929 (2010). DOI: $10.1016 /$ j.matdes.2009.07.031

[37] Duquesne S., Jama C., Le Bras M., Delobel R., Recourt P., Gloaguen J. M.: Elaboration of EVA-nanoclay systems- Characterization, thermal behaviour and fire performance. Composites Science and Technology, 63, 1141-1148 (2003). DOI: $\underline{10.1016 / \mathrm{S} 0266-3538(03) 00035-6}$

[38] Peeterbroeck S., Alexandre M., Jérome R., Dubois Ph.: Poly(ethylene-co-vinyl acetate)/clay nanocomposites: Effect of clay nature and organic modifiers on morphology, mechanical and thermal properties. Polymer Degradation and Stability, 90, 288-294 (2005). DOI: $10.1016 /$ j.polymdegradstab.2005.03.023 